\title{
Characteristics and health related quality of life in a population with advanced chronic obstructive pulmonary disease, a cross- sectional study
}

D. G. Bove B, $^{1,}$ (D, M. Lavesen ${ }^{1,2}$ and B. Lindegaard ${ }^{2}$

\begin{abstract}
Background: It is important to understand the total burden of COPD and thereby be able to identify patients who need more intensive palliative care to avoid deteriorated quality of life. The aim of this study was to describe the psychosocial and demographic characteristics of a population with advanced COPD in a stable phase of the disease.

Methods: This study was cross-sectional based on a prospective observational cohort. The following questionnaires were administered: Chronic Respiratory Disease Questionnaire (CRQ), The COPD Assessment Test (CAT), The Hospital and Anxiety and Depression Scale (HADS), The Medical Research Council dyspnoea scale (MRC), and self-rate general health.

Results: We included 242 patients with advanced COPD from a Danish pulmonary outpatient clinic. Their mean $\mathrm{FEV}_{1}$ was $38 \%( \pm 12.7)$ and $19 \%$ were treated with long term oxygen. The mean CRQ domain score was CRQdyspnea 4.21 ( \pm 1.4$)$, CRQ-Mastery 4.88 ( \pm 1.3$)$, CRQ-Emotional 4.81 ( \pm 1.2$)$, CRQ-Fatigue $3.93( \pm 1.3)$. The mean CATscore was 18.4 ( \pm 6.7 ), and $44 \%$ had a CAT score $>20$. The mean score on the subscale for anxiety (HADS-A) and depression (HADS-D) was $5.07( \pm 3.9)$ and $5.77( \pm 3.9)$, respectively. Thirty percent self-rated their health as bad or very bad and $19.8 \%$ were current smokers.

Conclusions: This study describes the characteristics of a population with advanced COPD in a stable phase of their disease. Our results illustrate how the population although treated in an outpatient structure already focusing on palliative needs, still live with unmet palliative needs and impaired quality of life.
\end{abstract}

Keywords: COPD, HRQoL, Non-malign palliative care, Patient-reported outcome, Psychosocial characteristics, Quality of life

\footnotetext{
* Correspondence: dorthe.gaby.bove.01@regionh.dk

'Emergency Department, Copenhagen University Hospital, Nordsjælland, Dyrehavevej 29, 3400 Hillerød, Denmark

${ }^{2}$ Department of Pulmonary \& Infectious Diseases, Copenhagen University

Hospital, Nordsjælland, Dyrehavevej 29, 3400 Hillerød, Denmark
}

(c) The Author(s). 2020 Open Access This article is licensed under a Creative Commons Attribution 4.0 International License, which permits use, sharing, adaptation, distribution and reproduction in any medium or format, as long as you give appropriate credit to the original author(s) and the source, provide a link to the Creative Commons licence, and indicate if changes were made. The images or other third party material in this article are included in the article's Creative Commons licence, unless indicated otherwise in a credit line to the material. If material is not included in the article's Creative Commons licence and your intended use is not permitted by statutory regulation or exceeds the permitted use, you will need to obtain permission directly from the copyright holder. To view a copy of this licence, visit http://creativecommons.org/licenses/by/4.0/. The Creative Commons Public Domain Dedication waiver (http://creativecommons.org/publicdomain/zero/1.0/) applies to the data made available in this article, unless otherwise stated in a credit line to the data. 


\section{Background}

The World Health Organization (WHO) estimates that 65 million people have moderate to severe chronic obstructive pulmonary disease (COPD) (http://www.who.int/respiratory/copd/burden/en/). In Denmark, approximately 320,000 persons have COPD and 50,000 of these have advanced COPD (https://www.lunge.dk/lunger/viden-noegletal-om-lungesygdomme). Worldwide, $5 \%$ of all deaths are caused by COPD corresponding to more than 3 million annual deaths. In Denmark, 5500 persons die due to COPD each year, making the disease the third most frequent cause of death in Denmark, and the highest mortality rate of COPD in the EU (https://www.lunge.dk/lunger/ viden-noegletal-om-lungesygdomme). There is growing evidence that patients with advanced COPD are marked by a high symptom burden, impaired health related quality of life (HRQoL) and live their last years of life with unmet palliative needs [1-5].

In the past years we have developed and implemented a new Danish pulmonary outpatient structure named CAPTAIN with the aim of improving the basic palliative care offered to patients with advanced COPD [6]. All patients were assigned to a CAPTAIN-nurse who were responsible for establishing and maintaining an individualized relationship with the patients and identifying their need for care and treatment. Routine patient controls were replaced with ad hoc physician consultations and planned advance care dialogues. Our qualitative evaluations illustrated how this new outpatient structure made it possible to respond to the individual and fluctuating palliative needs of patients with advanced COPD, and how both patients and health care professionals experienced that the quality of care improved. CAPTAIN is currently considered standard care for all patients with advanced COPD affiliated to our outpatient clinics [6-8].

Until now, the majority of studies investigating symptom burden and HRQoL in patients with COPD include mainly patients with COPD in a mild or moderate state and treated in traditional organizations with semi-annual or annual medical checks $[9,10]$. The explanation may be that it is difficult to recruit patients with advanced COPD to research projects, just like it requires special attention and devoted resources from the researchers to reduce missing data and dropouts. The CAPTAIN structure and assigned CAPTAIN-nurses gave us the opportunity to collect this data through validated questionnaires - either administered by self-report or interview, and thereby generate knowledge about the population with advanced COPD in a stable phase of the disease.

There is a need for knowledge about the symptom burden and HRQoL in patients with advanced COPD, living at home and treated in an outpatient structure that already focuses on the patients' individual basic palliative needs. HRQoL is arguable the most relevant outcome from a patient's perspective and associated with both COPD mortality and morbidity [9, 11-14]. Therefore, the aim of this study was to describe the psychosocial and demographic characteristics of a population with advanced COPD in a stable phase of the disease.

\section{Methods}

\section{Study design}

This study was cross-sectional based on a prospective cohort of patients with advanced COPD affiliated a pulmonary outpatient clinic at Nordsjællands Hospital, Denmark. In Denmark, only patients with advanced COPD are seen in a pulmonary outpatient clinic, otherwise they are cared for by their general practitioner. Advanced COPD was defined as a $\mathrm{FEV}_{1}$ less than $50 \%$ of predicted or a high symptom burden or two or more annual exacerbations [5]. CAPTAIN was standard care for all patients [6].

\section{Study population}

All patients affiliated or referred to the pulmonary outpatient clinic with the diagnosis COPD (ICD-10) could be included $(n=650)$. Exclusion criteria was inability to understand Danish or unwillingness to give informed consent.

Ten patients did not meet the inclusion criteria, 28 patients rejected to participate due to lack of resources, poor vision or fatigue and 50 patients verbally agreed to participate but were never included as they did not fulfill or return the informed consent. Three hundred twenty patients were not invited to participate by their nurse. The nurses' reason for this was either bustle and lack of time among the nurses, or because the nurses interpreted that the patients were in a too bad condition to participate or in acute phase of the disease.

A total of 242 patients with advanced COPD were enrolled in the period June 2017 to December 2018.

\section{Data colleting and data management}

The first and second author reviewed the patients' medicinal records for demographic and clinical data (Table 1). Weight, $\mathrm{FEV}_{1}$ and oxygen saturation were measured by inclusion. If this was not possible, the last measured values within the previous 12 months were recorded. Data about smoking and alcohol habits were patient reported at time of inclusion.

Patients completed self-reported or interview administrated questionnaires. All included patients were asked to fill out the following questionnaires: Chronic Respiratory Disease Questionnaire (CRQ), The COPD Assessment Test (CAT), The Hospital and Anxiety and Depression Scale (HASDS), The Medical Research Council dyspnoea scale (MRC), and in addition self-rate 
Table 1 Type of variables

\begin{tabular}{|c|c|}
\hline Characteristics & $\begin{array}{l}\text { Type of } \\
\text { quantity }\end{array}$ \\
\hline \multicolumn{2}{|l|}{ Sociodemographic } \\
\hline Age, height, weight & Continuous \\
\hline $\begin{array}{l}\text { Gender, ethnicity, marital, educational and } \\
\text { occupational status, living arrangements }\end{array}$ & Categorical \\
\hline Use of social services, smoking, alcohol, E-cigarettes & Binary $(\mathrm{Y} / \mathrm{N})$ \\
\hline \multicolumn{2}{|l|}{ Clinical and paraclinical } \\
\hline $\begin{array}{l}\mathrm{FEV}_{1} \text { of predicted value, oxygen saturation, } \\
\text { numbers of exacerbation within } 12 \text { months, BMI }\end{array}$ & Continuous \\
\hline $\begin{array}{l}\text { Oxygen treatment, treated with NIV within } \\
12 \text { months, }\end{array}$ & Binary $(\mathrm{Y} / \mathrm{N})$ \\
\hline \multicolumn{2}{|l|}{ Medications } \\
\hline SSRI, TCA, azapirones & Binary $(\mathrm{Y} / \mathrm{N})$ \\
\hline Benzodiazepines & Binary $(\mathrm{Y} / \mathrm{N})$ \\
\hline Opioids on the indication dyspnoea & Binary $(\mathrm{Y} / \mathrm{N})$ \\
\hline Permanent corticosteroid treatment & Binary $(\mathrm{Y} / \mathrm{N})$ \\
\hline $\begin{array}{l}\text { Weak analgesics and nonsteroidal } \\
\text { anti-inflammatory agents }\end{array}$ & Binary $(\mathrm{Y} / \mathrm{N})$ \\
\hline LAMA, LABA, ICS or combinations & Binary $(\mathrm{Y} / \mathrm{N})$ \\
\hline Cannabis oil & Binary $(\mathrm{Y} / \mathrm{N})$ \\
\hline \multicolumn{2}{|l|}{ Usual care } \\
\hline Pulmonary rehabilitation during the past 12 months & Binary $(\mathrm{Y} / \mathrm{N})$ \\
\hline Practical assistance, personal care, home nursing care & Binary $(\mathrm{Y} / \mathrm{N})$ \\
\hline Public appropriation for terminal care & Binary $(\mathrm{Y} / \mathrm{N})$ \\
\hline \multicolumn{2}{|l|}{ Mortality } \\
\hline Death & Binary $(\mathrm{Y} / \mathrm{n})$ \\
\hline Place of death & Categorical \\
\hline \multicolumn{2}{|l|}{ Standardised questionnaires } \\
\hline$C R Q, C A T, H A D S, M R C$ & Continuous \\
\hline Self-rated health & Categorical \\
\hline
\end{tabular}

FEV1 forced expiratory volume in $1 \mathrm{~s} ; B M I$ body mass index; NIV non-invasive ventilation; SSRI selective serotonin reuptake inhibitors; TCA tricyclic antidepressants; MRC Medical Research Council dyspnoea scale; CAT The COPD Assessment Test (CAT); CRQ Chronic Respiratory Disease Questionnaire; HADS Hospital and Anxiety and Depression Scale; $Y / N$ yes/no.

their general health. Licenses were obtained on all questionnaires before the start of the study and the standardised questionnaires were scored according to the guidelines from the instrument developers.

All data were entered into a RedCap database by DGB and $\mathrm{ML}$ and two independent student workers. Finally, the two student workers controlled $20 \%$ of all entered data and found minor data entry errors in three cases.

\section{Measurements}

The CRQ measure HRQoL in patients with respiratory diseases. We used the self-administrated standardized CRQ (CRQ-SAS) which consist of 20 items across four dimensions; Dyspnea (5 items), fatigue (4 items), emotions (7 items) and mastery (4 items). Patients answer each question on a seven points Likert-type scale to express the degree of disability from 1 (maximum impairment) to 7 (no impairment). The mean score of each domain is calculated and presented for interpretation (range 1-7). It is not recommended to present a summary score of the 20 items [15].

The CAT is a self-administered questionnaire that measures health status in patients with COPD. The CAT consists of 8 items (cough, phlegm tightness, breathlessness, limited activities, confidence leaving home, sleeplessness and energy) each assessing the impact on COPD on daily life and rated on a semantic differential scale from 0 to 5 . The total CAT score ranges between 0 (low impact) to 40 (high impact) [16]. A CAT-score between 10 and 20 points is defined as of medium impact on patients' HRQoL and COPD described as the most important problem patients have. A CAT-score > 20 points are described as COPD stops patients from doing most things that they want to do and with high impact on their HRQoL (http://www.catestonline.org/ images/UserGuides/CATHCPUser\%20guideEn.pdf).

The HADS is a self-completed questionnaire that measure symptoms of anxiety and depression in patients in non-psychiatric settings [17]. HADS consist of two subscales, where anxiety (HADS-A) and depression (HADS-D) are assessed as separate components each with seven items rated on a four-point scale from 0 (no symptoms present) to 3 (significant symptoms). The score on each subscale range from 0 to 21 . A score above 8 points on each subscale indicates clinically significant symptoms of anxiety and/or depression [18].

The MRC is a patient-rated single item scale where severity of dyspnea is rated by the patient from 1 to 5 . 'I only get breathless with strenuous exertion' is grade 1 and 'I am too breathless to leave the house' is grade 5 . An MRC $\geq 3$ is a threshold for separating less breathlessness from more breathlessness $[5,19]$.

\section{Statistical methods}

All variables were analysed in a descriptive manner (Table 1). Parametric data were analyzed using means, standard deviations (SD) and ranges, and nonparametric data with medians and interquartile ranges (IQR). Comparison between means was conducted with t-tests. The association between mortality (outcome) and the four instruments (CRQ, HADS, CAT, and MRC) (exposures) was tested using a multivariable logistic regression analysis with gender and age adjustment. Statically significant results were defined as those with $p<0.05$. Statistical analysis was performed using SPSS v.22 (IBM Corp., Armonk, NY, USA).

There are two main types of missing data; missing forms or missing items. In missing forms, the whole 
questionnaire is missing, while missing items refer to one or several items in the questionnaire is not completed. In this study, all questionnaires not $100 \%$ completed are excluded from the analysis, which is why the numbers (n) varies in Tables 1 and 3.

\section{Results}

Demographic and clinical baseline characteristics of the included patients $(n=242)$ are presented in Table 2 . The patients were aged 39-91 years with a mean of 72 years (8.4) and 58\% were females. Except for one patient, all had an ethnicity of Danish origin. One fifth of the patients were current smokers and more than $13 \%$ consumed more alcohol than recommended by the Danish National Board of Health.

Patients demonstrated a mean FEV1 of $38 \%$ of predicted value (12.7), and $19 \%$ were treated in their home with long term oxygen. In addition, $12 \%$ of the patients had been treated with NIV in the previous 12 months and $66 \%$ (the sum of patients with 1 or 2 exacerbations and those with $>2$ exacerbations) of the patients had one or more exacerbations within the last 12 months.

Selected pharmacological preparations extracted from the patient's record is presented in Table 3 . Nearly $50 \%$ of the patients were treated for pain (weak analgesics, NSAID or opioids). Thirteen patients (6\%) were treated with opioids to relieve their dyspnea, whereas only one patient was treated with cannabis oil. Thirty-two patients (13\%) were treated with antidepressant, ten $(4 \%)$ with antipsychotics and six-teen (7\%) with benzodiazepines.

More than $50 \%$ of the patients were prescribed triple therapy (ICS/LABA/LAMA) and the rest a two-drug combination. Only seven patients received single drug treatment. Not surprisingly, more than $90 \%$ were prescribed short acting bronchodilators.

Table 4 shows the patient reported psychosocial outcomes assessed by the standardised questionnaires. The CRQ assessed HRQoL based on four domains. Each domain was scored separately, and higher scores indicated better quality of life. On average did the patients have a CRQ-D score of 4.21 points, CRQ-M of 4.88 points, CRQ-E of 4.81 points and CRQ-F of 3.93 points. The patients had on average the lowest score on the fatigue domain indicating most HRQoL impairment compared to the domains: dyspnea, mastery and emotion. However, all patients experienced impairment in all domains.

The mean CAT-score was 18.41 points. Forty-four percent had a CAT score $\geq 20$ points and more than $90 \%$ a score $\geq 10$ points. The mean MRC was 3.35 points and $73 \%$ had an MRC score $\geq 3$.

Sixty patients (32\%) had a HADS-D subscale score $\geq 8$ point and forty-five patients (24\%) a HADS-A subscale score $\geq 8$ points. Thirteen percent of the patients had a both HADS A and a HADS D score $\geq 8$ point.
More than half of the patients rated their health as reasonable and $30 \%$ as bad or very bad. However, $18.5 \%$ rated their health as very good or good.

Twenty-nine patients died during the data collection period of 1.5 year corresponding to a crude mortality rate of $12 \%$. The majority, $70 \%$ died in the hospital, $24 \%$ died at home and $6 \%$ died at hospice. The patients who died consisted of $58.6 \%$ males, and $66 \%$ were living alone. On average $31 \%$ of the patients who died rated their health as bad or very bad. Their mean CRQdomain scores were: CRQ-D $3.7( \pm 1.4)$, CRQ-F $3.4( \pm$ 1.4), CRQ-E $4.5( \pm 1.4)$, CRQ-M $4.6( \pm 1.5)$. Their mean CAT score was $18.54( \pm 4.6)$. They had a mean HADS-A score of 6.6 points $( \pm 5.3)$ and a HADS-D score of $7.3( \pm$ 5.1). The patients $(n=29)$ who died had an average of 1.52 points [ $95 \% \mathrm{CI}, 0.10$ to 2.94 ] higher HADS-D score compare to the rest of the patients $(p=0.0454)$. On the HADS-A, the difference was on average 1.51 points [ $95 \% \mathrm{CI}, 0.07$ to 2.95$]$ higher score $(p=0.049)$. The frequency of $\geq 2$ annual exacerbations were $41.4 \%$ in the patients who died compared to $34.1 \%$ among the rest of the patients. A multi logistic regression analysis did not show any significant association between mortality and CAT, MRC, CRQ, and HADS scores with and without adjustments for age and gender (data not shown). There was a significant association between age and mortality OR: $1.09,[1.001 ; 1.18] p=0.05$.

\section{Data completeness of administrated questionnaires}

The overall data quality in terms of completed and returned questionnaires was acceptable, as all questionnaires expect self-rated health had a completeness > $80 \%$. The completeness ranged between $76 \%$ for selfrated health to $93 \%$ for the CAT. Missing data present a serious problem in any study, and it is always an issue whether those who completed the questionnaires differ from those missing. Based on rule of thumps missing data between 5 and $20 \%$ is acceptable and considered expected and realistic in a population marked by severe disease [20-22].

\section{Discussion}

Our study contributes knowledge of the psychosocial status of patients with advanced COPD in a stable phase of the disease and show a widespread level of HRQoL impairment. Nearly all patients had a CAT score $\geq 10$ points and more than $44 \%$ a CAT-score $\geq 20$ points. The Global Initiative for Chronic Obstructive Lung Disease (GOLD) recommend a CAT score $\geq 10$ points as a threefold for considering treatment for symptoms [5] which comply with the recommendations of offering all patients with advanced COPD early integrated palliative care $[11,23,24]$. 
Table 2 Demographic and clinical characteristics of the patients $(n=242)$

\begin{tabular}{llll}
\hline Characteristics & $\boldsymbol{N}(\%)$ & Mean \pm SD & Range \\
\hline Gender, females & 140 & & \\
& $(57.9)$ & & \\
Age, year & & $72.01 \pm 8.40$ & $39-91$ \\
Ethnicity, Danish origin & 241 & & \\
& $(99.6)$ & & \\
Body Mass Index $\left(\mathrm{kg} / \mathrm{m}^{2}\right)$ & & $25.11 \pm 6.20$ & $11-44$ \\
$\begin{array}{l}\text { Smoking and alcohol consumption } \\
\text { Current smoker }\end{array}$ & & & \\
& $(18.8)$ & & \\
$\begin{array}{l}\text { Current E-cigarette user } \\
\text { More than 7 units of alcohol per }\end{array}$ & $7(2.9)$ & & \\
week for women and 14 units for & $(13.6)$ &
\end{tabular}

\section{Living arrangements}

$\begin{array}{ll}\text { Living alone } & 102 \\ & (42.1) \\ \text { Nursing home resident } & 3(1.2)\end{array}$

Educational and occupational status

$\begin{array}{ll}\text { No education } & 16 \\ & (6.6) \\ \text { Medium academic or trade } & 129 \\ & (53.3) \\ \text { Academic } & 21 \\ & (8.7) \\ \text { Retired due to health or age } & 215 \\ & (88.8) \\ \text { Employed } & 18 \\ & (7.4)\end{array}$

\section{Social network}

The presence of a well-functioning 225

and solid network, self-rated (93.0)

\section{Use of social services delivered by the municipality}

$\begin{array}{ll}\text { Help with personal care } & 36 \\ & (14.9) \\ \text { Help solving practical tasks } & 57 \\ & (23.6) \\ \text { Primary nurse care } & 30 \\ & (12.4)\end{array}$

\section{Pulmonary function and oxygen therapy}

Long term oxygen therapy $\quad 46$

(19.0)

$\mathrm{FEV}_{1} \%$ of predicted value
Saturation $\mathrm{O}_{2}$

$\mathrm{FEV}_{1} \%$ of predicted value

Non-Invasive Ventilation (NIV) the previous 12 months $^{a}(n=229$ a) NIV

Exacerbations treated with systemic corticosteroids, antibiotics, or both the previous 12 months $(n=237 \mathrm{a})$

No exacerbations
Table 2 Demographic and clinical characteristics of the patients $(n=242)$ (Continued)

\begin{tabular}{|c|c|}
\hline Characteristics & $N(\%) \quad M e a n \pm S D$ \\
\hline 1 or 2 exacerbations & $\begin{array}{l}107 \\
(45.14)\end{array}$ \\
\hline More than 2 exacerbations & $\begin{array}{l}49 \\
(20.74)\end{array}$ \\
\hline
\end{tabular}

Pulmonary rehabilitation $^{b}$ the previous 6 months $^{a}$

$\begin{array}{ll}\text { Participated }{ }^{c} \text { in pulmonary } & 58 \\ \text { rehabilitation* } & (24.0)\end{array}$

Results expressed are numbers (n), Percentages (\%), means with standard deviations (SD) and ranges.

${ }^{a}$ Previous 6 or 12 months refers to the time from baseline and 6 or 12 months back in time

${ }^{b}$ Pulmonary rehabilitation includes physical training combined with patient education and has a duration of 10 weeks. 'Participating is defined as at least $50 \%$ attendance. aThe actual number included in the analysis

Although the patients in our study were treated in an altered outpatient structure focusing on the patients' basic palliative needs $[6,7]$, our patients still lived with impaired HRQoL. However, we cannot know if our population's HRQoL actually were higher compared to patients treated in traditional outpatient clinics. Nibber et al. found in a retrospective cohort of patients with severe/very severe COPD a mean (SD) CAT-score of 26.1 (7.6) points [25], which is significantly higher than our mean CAT-score of 18.41 (6.7) points.

Table 3 Concomitant medication

\begin{tabular}{|c|c|}
\hline Pharmacological variables $(\boldsymbol{n}=242)$ & n (\%) \\
\hline \multicolumn{2}{|l|}{ Regularly orally administered medication } \\
\hline $\begin{array}{l}\text { Weak analgesics and nonsteroidal anti-inflammatory agents } \\
\text { (NSAID) }\end{array}$ & $82(33.9)$ \\
\hline Opioids on indication pain & $29(12.0)$ \\
\hline Opioids on indication dyspnea & $13(5.4)$ \\
\hline Benzodiazepines & $16(6.6)$ \\
\hline Antidepressants & $32(13.2)$ \\
\hline Antipsychotics & $10(4.1)$ \\
\hline Cannabis oil & $1(0.4)$ \\
\hline \multicolumn{2}{|l|}{ Regularly inhaled medication } \\
\hline Short acting bronchodilaters & $\begin{array}{l}219 \\
(90.5)\end{array}$ \\
\hline $\operatorname{LAMA}^{a}$ & $3(1.2)$ \\
\hline$\angle A B A^{b}$ & $3(1.2)$ \\
\hline $\mathrm{ICS}^{\mathrm{C}}$ & $1(0.4)$ \\
\hline$L A M A+L A B A$ & $85(35.1)$ \\
\hline$I C S+L A B A$ & $8(3.3)$ \\
\hline ICS + LAMA & $2(0.8)$ \\
\hline$I C S+L A B A+L A M A$ & $\begin{array}{l}138 \\
(57.0)\end{array}$ \\
\hline
\end{tabular}


Table 4 Patient-reported psychosocial variables assessed by the questionnaires CRQ. HADS, CAT, MRC and self-rated health

\begin{tabular}{|c|c|c|c|}
\hline Questionnaires & Mean $\pm S D$ & N (\%) & Range \\
\hline \multicolumn{4}{|c|}{ Quality of life according to $C R Q\left(n=201^{\mathrm{a}}\right)$} \\
\hline CRQ-D & $4.21 \pm 1.44$ & & $1-7$ \\
\hline CRQ-M & $4.88 \pm 1.32$ & & $1-7$ \\
\hline CRQ-E & $4.81 \pm 1.24$ & & $1-7$ \\
\hline CRQ-F & $3.93 \pm 1.30$ & & $1-7$ \\
\hline \multicolumn{4}{|c|}{ Depression and anxiety according to HADS $\left(n=194^{\mathrm{a}}\right)$} \\
\hline HADS-A & $5.07 \pm 3.92$ & & $0-17$ \\
\hline HADS-D & $5.77 \pm 3.89$ & & $0-19$ \\
\hline \multicolumn{4}{|c|}{ Quality of life according to $C A T\left(n=225^{\mathrm{a}}\right)$} \\
\hline CAT & $18.41 \pm 6.68$ & & $2-38$ \\
\hline \multicolumn{4}{|c|}{ Functional dyspnoea according to $\operatorname{MRC}\left(n=209^{a}\right)$} \\
\hline MRC & $3.35 \pm 1.12$ & & $1-5$ \\
\hline \multicolumn{4}{|c|}{ Self-rated health $\left(n=183^{\mathrm{a}}\right)$} \\
\hline Very good & & $12(6.6)$ & \\
\hline Good & & $22(12.0)$ & \\
\hline reasonable & & $93(50.8)$ & \\
\hline Bad & & $45(24.6)$ & \\
\hline Very bad & & $11(6.0)$ & \\
\hline
\end{tabular}

CRQ domain scores with values from 1 (largest impairment) to 7 (no impairment). Each HADS subscale scores with values from 0 to 21 (high score corresponds to level of symptoms). CAT scores from 0 to 20 (high scores correspond to level of impairment). MRC scores from 1 to 5 (high score correspond to high intensity of dyspnea). ${ }^{\text {a }}$ The actual number included in the analysis.

According to the CRQ was fatigue the problem affecting the patients' HRQoL most. Fatigue is a cardinal but multifaceted symptom of advanced COPD and described as a profound feeling of physical and psychological wariness that is not relieved by sleep or rest $[11,26]$. Studies report fatigue prevalences in patients with advanced COPD to 71 and $96 \%$ in palliative patients [26]. Fatigue do often co-exist with breathlessness and cough in what is called the respiratory cluster [11, 27], just like fatigue is associated with depression and anxiety [28].

In this study the prevalences of anxiety and depression were within the ranges of what is previous described for COPD outpatients in a stable phase of the disease [28]. However, it is worth noticing that $13 \%$ of the patients did suffer both symptoms of anxiety and depression; a known condition with heightened risk of suicidal ideation, increased physical disability and chronic depressive symptoms $[29,30]$. The frequency of patients treated with benzodiazepines in this study were lower than reported by Vozoris et al. in a population of older adults with COPD [31]. Nearly $50 \%$ of patients in this study were treated for pain which correspond to the findings of others reporting prevalences of pain ranging from 32 to $77 \%$ in patients with all stage COPD [32, 33].
However, little is known about the cause and level of pain in patients with advanced COPD and how pain is effectively managed both pharmacological and nonpharmacological in this population [33]. It can be assumed that the cause of pain in patients with advanced COPD can be muscular, related to osteoporosis, arthritis or other comorbidities just like pain properly will be associated with anxiety, depression and dyspnea. Further research is recommended.

The patients who died $(n=29)$ had a clinically significant higher level of anxiety and depression compared to the rest of the patients [17], although it did not show in impaired HRQoL assessed by the CRQ or CAT. In this study, the prevalence of two or more annual exacerbations were more frequent among the patients who died compared to the rest of the patients. This result is not surprising as it is well known that COPD patients with comorbid anxiety and/or depression have a higher risk of exacerbations and mortality after exacerbations, compared to patients without these comorbidities [12, 34, 35]. The majority of the patients died in the hospital, which mirror other studies results, although the patients' general preference is to die at home [11,36-38].

It is thought-provoking that despite the population was characterized by severe pulmonary disease, one-fifth was current smokers. Although patients with advanced COPD are in the last stage of the disease and presumably have a limited life span, smoking cessation still makes sense and contribute to prevent further deterioration $[5,39]$. In Denmark, smoking cessation courses are free but requires attendance at a given location outside the patients' home. Transport are a known barrier for patients with advanced COPD and a significant reason that they do not profit from health promotion intervention outside their home $[40,41]$. It would have been interesting if we had collected data on whether smoking patients had been offered smoking cessation interventions in form of pharmacology, non-pharmacological or combinations. Our results underpin a need for further knowledge about how to motivate and support patients with advanced COPD with smoking cessation.

With this study we have described the characteristics of a population with advanced COPD. The prevalences of high CAT, MRC, HADS, or low CRQ scores were high, and indicate a need for a more intensive palliative care intervention than actually offered. Intensive palliative care should be individualized and address the needs that are currently most relevant to the patient concerned. Systematic screening of the symptom burden using validated questionnaires could be a method of targeting and intensifying a palliative effort.

Our results illustrate that if we for example define a CAT-score above 20 points as an indicator for intensified palliative needs [5], the target population will be 
huge and at the same time not target the patients who die as they had a mean CAT score of 18 points. In Denmark 50,000 patients suffer from severe COPD [2]. It may be assumed that many of them have a CAT score above 20 points, and if $44 \%$ of these patients were offered intensified palliative care this alone would correspond to 22,000 patients. In addition, our population may not be fully representative for the general population of patients with severe COPD. Our patients are already treated in a palliative care setting [6], and the percentages with a CAT scores above 20 points may therefore be even higher than the $44 \%$ in a general COPD population.

In Denmark, specialized palliative care is initially developed and targeted to cancer patients and organized in oncology. Currently, the need for specialized palliation and hospice stays among Danish cancer patients exceeds the current capacity and patients with cancer are often waitlisted before receiving a palliative offer (www.repha. $\mathrm{dk}$ ). More than $95 \%$ of the specialized palliative resources in Denmark are used on cancer patients, and only few COPD patients are offered specialized palliative care or admitted to a hospice [42-45]. The size of the COPD population with unmet palliative needs makes it, in our opinion, unrealistic to think that patients with advanced COPD can be accommodated into existing specialized palliative offers. We recommend that future research and initiatives aiming at improving palliative care for COPD patients take the COPD population size into consideration. If we want to offer early and integrated palliative care and be able to accommodate the size of the COPD population, we have to reflect on how to use and expand our existing outpatient structures and competences among pulmonary nurses and physicians in a formalized collaboration with the specialized palliation.

\section{Limitations and strengths of this study}

This study has several limitations. The exact numbers and reason for not participating are not registered systemically, and we cannot know if the patients included are representative for the population with advanced COPD. It can be assumed that the patients included in this study and willing to complete several questionnaires are those who are least affected by their disease and thereby those with the best quality of life. We see the following strengths of our study. First, it was possible for us to include patients with advanced COPD. Second, our study sample was rather large compared to other studies investigating the symptom burden and quality of life in patients with advanced COPD [46, 47]. Third, our patients were treated in an described outpatient structure based on existing guidelines for patients with advanced COPD [6-8]. Fourth, we only used validated questionnaires [14, 18, 48-51].

\section{Conclusion}

This study describes the characteristics of a population with advanced COPD in a stable phase of the disease. If a CAT-score above 20 points are used as an indicator for intensified palliative needs in patients with COPD, the target population will be huge and at the same time not target the patients who die. Our results illustrate how the population, although treated in an outpatient structure already focusing on palliative needs, still live with unmet palliative needs and impaired HRQoL and how one out of five patients currently smokes.

\section{Abbreviations \\ BMI: Body Mass Index; CAT: The COPD Assessment Test; CRQ: The Chronic Respiratory Disease Questionnaire; COPD: Chronic Obstructive Pulmonary Disease; $\mathrm{FEV}_{1}$ : Forced Expiratory Volume in $1 \mathrm{~s}$; HADS: The Hospital and Anxiety and Depression Scale; HRQoL: Health Related Quality of Life; MRC: The Medical Research Council Dyspnoea Scale; NIV: Non-invasive ventilation; NSAID: Nonsteroid Anti-inflammatory Agents; SSRI: Selective Serotonin Reuptake inhibitors; TCA: Tricyclic Antidepressant; WHO: World Health Organization}

\section{Acknowledgments}

The authors would like to thank the patients with advanced COPD who despite their advanced disease made it a priority to participate and thereby provided the data for this study. Moreover, we owe a special thanks to all the CAPTAIN-nurses affiliated the outpatient clinic at Nordsjæellands Hospital.

\section{Authors' contributions}

All authors contributed substantial toward data analysis, drafting and revising the paper and agree to be accountable for all aspect of the work. All authors contributed to the design of the study. DGB and ML collected and managed the data. DGB and BL performed the statistical analyzes and all authors contributed to the discussion and interpretation of the results. DGB lead on the manuscript preparation, but all authors have read and approved the manuscript

\section{Funding}

The study was financially support by The Danish Lung Association Fund and The Danish Nursing Council's (DSR) research fund.

\section{Availability of data and materials}

The datasets analysed during this study are available from the corresponding author on reasonable request.

\section{Ethics approval and consent to participate}

Patients were informed about the study in writing as well as verbally, and only included when they provided written consent for their participation. Patients were informed that they could withdraw from the study at any time and with no implications for their future treatment. Those who left the study for other reasons than death where kindly asked for permission to use their previous data.

Furthermore the study was approved by the Chief Executives at

Nordsjællands Hospitals' Department of Pulmonary and Infectious Diseases in Denmark. The Ethics Committee (www.nvk.dk) in Denmark, the Biomedical Research Ethics Committee System Act was questioned, and they decided that the study was not required to report (H-17001509). All patients' data were handled and stored in accordance with the Danish Data Protection Agency (05204, NOH-2017-001).

Consent for publication

Not applicable.

Competing interests

The authors declare that they have no competing interests. 
Received: 2 September 2019 Accepted: 15 June 2020 Published online: 18 June 2020

\section{References}

1. Disler RT, Green A, Luckett T, Newton PJ, Inglis S, Currow DC, Davidson PM. Experience of advanced chronic obstructive pulmonary disease: metasynthesis of qualitative research. J Pain Symptom Manag. 2014.

2. Sundh J, Johansson G, Larsson K, Linden A, Lofdahl CG, Janson C, Sandstrom T. Comorbidity and health-related quality of life in patients with severe chronic obstructive pulmonary disease attending Swedish secondary care units. Int J Chron Obstruct Pulmon Dis. 2015:10:173-83.

3. Schroedl CJ, Yount SE, Szmuilowicz E, Hutchison PJ, Rosenberg SR, Kalhan R A qualitative study of unmet healthcare needs in chronic obstructive pulmonary disease. A potential role for specialist palliative care? Ann Am Thorac Soc. 2014;11(9):1433-8.

4. Marx G, Nasse M, Stanze H, Boakye SO, Nauck F, Schneider N. Meaning of living with severe chronic obstructive lung disease: a qualitative study. BMJ Open. 2016:6(12):e011555 -2016-011555.

5. Global Initiative for Chronic Obstructive Lung Disease: Global strategy for the diagnosis, management, and prevention of chronic obstructive pulmonary disease (GOLD 2019). Avaible from http://goldcopd.org/. 2019, 2019:

6. Lavesen M, Marsa KB, Bove DG. A new way of organising palliative care for patients with severe chronic obstructive pulmonary disease. Int J Palliat Nurs. 2018;24(2):64-8.

7. Bove DG, Jellington MO, Lavesen M, Marsa K, Herling SF. Assigned nurses and a professional relationship: a qualitative study of COPD patients perspective on a new palliative outpatient structure named CAPTAIN. BMC Palliat Care. 2019;18(1):24 -019-0410-0.

8. Bove DG, Lavesen M, Jellington MO, Marsaa KB, Herling SF. First year experiences with a palliative out-patients structure for patients with COPD: a qualitative study of health professionals' expectations and experiences. BMC Palliat Care. 2018;17(1):113 -018-0369-2

9. Henoch I, Strang S, Lofdahl CG, Ekberg-Jansson A. Health-related quality of life in a nationwide cohort of patients with COPD related to other characteristics. Eur Clin Respir J. 2016:3:31459.

10. Raherison C, Ouaalaya EH, Bernady A, Casteigt J, Nocent-Eijnani C, Falque L, Le Guillou F, Nguyen L, Ozier A, Molimard M. Comorbidities and COPD severity in a clinic-based cohort. BMC Pulm Med. 2018;18(1):117 -018-0684-7.

11. Maddocks M, Lovell N, Booth S, Man WD, Higginson IJ. Palliative care and management of troublesome symptoms for people with chronic obstructive pulmonary disease. Lancet. 2017;390(10098):988-1002.

12. Pooler A, Beech R. Examining the relationship between anxiety and depression and exacerbations of COPD which result in hospital admission: a systematic review. Int J Chron Obstruct Pulmon Dis. 2014;9:315-30.

13. Lou P, Zhu Y, Chen P, Zhang P, Yu J, Wang Y, Chen N, Zhang L, Wu H, Zhao $J$. Interaction of depressive and anxiety symptoms on the mortality of patients with COPD: a preliminary study. COPD. 2014;11(4):444-50.

14. Soriano JB, Lamprecht B, Ramirez AS, Martinez-Camblor P, Kaiser B, Alfageme I, Almagro P, Casanova C, Esteban C, Soler-Cataluna JJ, de Torres JP, Miravitlles M, Celli BR, Marin JM, Puhan MA, Sobradillo P, Lange P, Sternberg AL, Garcia-Aymerich J, Turner AM, Han MK, Langhammer A, Leivseth L, Bakke $P$, Johannessen A, Roche N, Sin DD. Mortality prediction in chronic obstructive pulmonary disease comparing the GOLD 2007 and 2011 staging systems: a pooled analysis of individual patient data. Lancet Respir Med. 2015;3(6):443-50

15. Guyatt GH, Berman L, Townsend M, Pugsley S, Chambers L. A measure of quality of life for clinical trials in chronic lung disease. Thorax. 1987:42:773-8.

16. Gupta N, Pinto LM, Morogan A, Bourbeau J. The COPD assessment test: a systematic review. Eur Respir J. 2014;44(4):873-84.

17. Zigmond AS, Snaith RP. The hospital anxiety and depression scale. Acta Psychiatr Scand. 1983;67(6):361-70.

18. Bjelland I, Dahl AA, Haug T, Neckelmann D. The validity of the hospital anxiety and depression scale. An updated literature review. J Psychosom Res. 2002;52(2):69-77.

19. Bestall JC, Paul EA, Garrod R, Garnham R, Jones PW, Wedzicha JA. Usefulness of the Medical Research Council (MRC) dyspnoea scale as a measure of disability in patients with chronic obstructive pulmonary disease. Thorax. 1999:54(7):581-6.

20. Gul RB, Ali PA. Clinical trials: the challenge of recruitment and retention of participants. J Clin Nurs. 2010;19(1-2):227-33.
21. Schulz KF, Grimes DA. Sample size slippages in randomised trials: exclusions and the lost and wayward. Lancet. 2002;359(9308):781-5.

22. Fayers PM, Machin D. Quality of Life. The assessment, analysis and interpretation of patient-reported outcomes. 2nd ed. The Atrium, Southern Gate, Chichester: Wiley; 2009.

23. Sundhedsstyrelsen [Danish Health Authority]: Anbefalinger for den palliative indsats [recommendations for palliative care]. 2017, (1.0):

24. Siouta N, van Beek K, Preston N, Hasselaar J, Hughes S, Payne S, Garralda E, Centeno C, van der Eerden M, Groot M, Hodiamont F, Radbruch L, Busa C, Csikos A, Menten J. Towards integration of palliative care in patients with chronic heart failure and chronic obstructive pulmonary disease: a systematic literature review of European guidelines and pathways. BMC Palliat Care. 2016;15(1):18 -016-0089-4.

25. Nibber A, Chisholm A, Soler-Cataluna JJ, Alcazar B, Price D, Miravitlles M. Validating the concept of COPD control: a real-world cohort study from the United Kingdom. COPD. 2017;14(5):504-12.

26. Lewko A, Bidgood P, Jewell A, Garrod R. A comprehensive literature review of copd-related fatigue. Curr Resp Med Rev. 2012;8(5):370-82.

27. Jenkins BA, Athilingam P, Jenkins RA. Symptom clusters in chronic obstructive pulmonary disease: a systematic review. Appl Nurs Res. 2019;45:23-9.

28. Yohannes AM, Kaplan A, Hanania NA. Anxiety and depression in chronic obstructive pulmonary disease: recognition and management. Cleve Clin J Med. 2018:85(2 Suppl 1):S11-8.

29. Yohannes AM, Alexopoulos GS. Depression and anxiety in patients with COPD. Eur Respir Rev. 2014;23(133):345-9.

30. Willgoss TG, Yohannes AM. Anxiety disorders in patients with COPD: a systematic review. Respir Care. 2013;58(5):858-66.

31. Vozoris NT, Fischer HD, Wang X, Anderson GM, Bell CM, Gershon AS, Stephenson AL, Gill SS, Rochon PA. Benzodiazepine use among older adults with chronic obstructive pulmonary disease: a population-based cohort study. Drugs Aging. 2013;30(3):183-92.

32. Bentsen SB, Miaskowski C, Cooper BA, Christensen VL, Henriksen AH, Holm AM, Rustoen T. Distinct pain profiles in patients with chronic obstructive pulmonary disease. Int J Chron Obstruct Pulmon Dis. 2018;13:801-11.

33. van Dam van Isselt EF, Groenewegen-Sipkema KH, Spruit-van Eijk M Chavannes NH, de Waal MW, Janssen DJ, Achterberg WP. Pain in patients with COPD: a systematic review and meta-analysis. BMJ Open. 2014;4(9): e005898 -2014-005898.

34. Hillas G, Perlikos F, Tsiligianni I, Tzanakis N. Managing comorbidities in COPD. Int J Chron Obstruct Pulmon Dis. 2015;10:95-109.

35. Lecheler L, Richter M, Franzen DP, Rampini SK, Cheetham M, Jenewein J, Battegay $E$, Nowak A. The frequent and underrecognised co-occurrence of acute exacerbated COPD and depression warrants screening: a systematic review. Eur Respir Rev. 2017;26(144). https://doi.org/10.1183/16000617.00262017 Print 2017 Jun 30.

36. Gomes B, Calanzani N, Gysels M, Hall S, Higginson IJ. Heterogeneity and changes in preferences for dying at home: a systematic review. BMC Palliat Care. 2013;12:7-684X-12-7

37. Higginson IJ, Reilly CC, Bajwah S, Maddocks M, Costantini M, Gao W GUIDE_Care project: which patients with advanced respiratory disease die in hospital? A 14-year population-based study of trends and associated factors. BMC Med. 2017;15(1):19 -016-0776-2.

38. Skorstengaard $M H_{\text {, Jensen } A B}$, Andreassen $P$, Brogaard $T$, Brendstrup $E_{\text {, }}$ Lokke A, Aagaard S, Wiggers H, Neergaard MA. Advance care planning and place of death, hospitalisation and actual place of death in lung, heart and cancer disease: a randomised controlled trial. BMJ Support Palliat Care. 2019.

39. Dalgliesh V, Pinnock H. Pharmacological Management of People Living with endstage chronic obstructive pulmonary disease. Drugs Aging. 2017;34(4):241-53.

40. Keating A, Lee A, Holland AE. What prevents people with chronic obstructive pulmonary disease from attending pulmonary rehabilitation? A systematic review. Chron Respir Dis. 2011;8(2):89-99.

41. Keating A, Lee AL, Holland AE. Lack of perceived benefit and inadequate transport influence uptake and completion of pulmonary rehabilitation in people with chronic obstructive pulmonary disease: a qualitative study. J Physiother. 2011;57(3):183-90.

42. Mousing CA, Timm H, Lomborg K, Kirkevold M. Barriers to palliative care in people with chronic obstructive pulmonary disease in home care: a qualitative study of the perspective of professional caregivers. J Clin Nurs. 2017.

43. Dalgaard KM, Bergenholtz H, Nielsen ME, Timm H. Early integration of palliative care in hospitals: a systematic review on methods, barriers, and outcome. Palliat Support Care. 2014;12(6):495-513. 
44. Danmarks Lungeforening og Palliativt Videnscenter: Palliativ indsats til KOLpatienter [Palliative Care for COPD patients]. En deskriptiv undersøgelse af danske KOL-patienters sygdomsforløb og behov for palliativ indsats. 2013, :

45. Hansen MB, Adsersen M, Grønvold M. Dansk Pallitiv Database [Danish palliative database]. Årsrapport 2017. DMCG-PAL; 2018.

46. Blinderman CD, Homel P, Billings JA, Tennstedt S, Portenoy RK. Symptom distress and quality of life in patients with advanced chronic obstructive pulmonary disease. J Pain Symptom Manag. 2009;38(1):115-23.

47. Reddy SK, Parsons HA, Elsayem A, Palmer JL, Bruera E. Characteristics and correlates of dyspnea in patients with advanced cancer. J Palliat Med. 2009; 12(1):29-36.

48. Puhan MA, Frey M, Buchi S, Schunemann HJ. The minimal important difference of the hospital anxiety and depression scale in patients with chronic obstructive pulmonary disease. Health Qual Life Outcomes. 2008;6: $467525-6-46$.

49. Schunemann HJ, Puhan M, Goldstein R, Jaeschke R, Guyatt GH. Measurement properties and interpretability of the chronic respiratory disease questionnaire (CRQ). COPD. 2005;2(1):81-9.

50. Schunemann HJ, Goldstein R, Mador MJ, McKim D, Stahl E, Puhan M, Griffith LE, Grant B, Austin P, Collins R, Guyatt GH. A randomised trial to evaluate the self-administered standardised chronic respiratory questionnaire. Eur Respir J. 2005;25(1):31-40.

51. Nowak C, Sievi NA, Clarenbach CF, Schwarz El, Schlatzer C, Brack T, Brutsche M, Frey M, Irani S, Leuppi JD, Rudiger J, Thurnheer R, Kohler M. Accuracy of the hospital anxiety and depression scale for identifying depression in chronic obstructive pulmonary disease patients. Pulm Med. 2014;2014: 973858

\section{Publisher's Note}

Springer Nature remains neutral with regard to jurisdictional claims in published maps and institutional affiliations.

Ready to submit your research? Choose BMC and benefit from:

- fast, convenient online submission

- thorough peer review by experienced researchers in your field

- rapid publication on acceptance

- support for research data, including large and complex data types

- gold Open Access which fosters wider collaboration and increased citations

- maximum visibility for your research: over $100 \mathrm{M}$ website views per year

At BMC, research is always in progress.

Learn more biomedcentral.com/submissions 